Martina Vajdić

CROATIAN POWER EXCHANGE Ltd

Croatia

Marko Kelava

CROATIAN POWER EXCHANGE Ltd

Croatia

\title{
Development and Impact of Flow-Based Methodology in Core Region
}

\section{SUMMARY}

The Core Flow-Based Market Coupling Project (Core FB MC) focuses on the development and implementation of the day-ahead market activities in the Core Capacity Calculation Region (Core CCR) within the Single Day-Ahead Coupling (SDAC). The Transmission System Operators (TSO) and Nominated Electricity Market Operators (NEMO) of the Core CCR aim to introduce FB MC at the regional level and ultimately, to facilitate the merger of regional markets and the creation of a fully integrated European Internal Energy Market.

Flow-Based Market is currently deployed within the Single Day-Ahead Coupling across Central Western Europe (CWE) covering Austria, Belgium, France, Germany, Luxemburg and the Netherlands. Within the Core Flow-Based Market Coupling project, all borders of the Core CCR will be coupled based on the Flow-Based capacity calculation methodology developed in the framework of the Capacity Allocation and Congestion Management (CACM) Regulation. The Core CCR consists of the bidding zone borders between the following EU Member States' bidding zones: Austria, Belgium, Croatia, Czech Republic, France, Germany, Hungary, Luxembourg, the Netherlands, Poland, Romania, Slovakia and Slovenia.

The Flow-Based Methodology is a methodology in which physical network constraints are obtained based on the available constraints on the critical elements of the network (branch) and the power transmission allocation factors that are defined for each critical branch and each zone (Bidding Zone) within Core CCR. These factors describe how the position of each bidding zone changes when the energy flow in the critical branch changes. The computer algorithm then seeks an optimal exchange of energy between the bidding zones.

Compared to the existing Net Transmission Capacity (NTC) methodology, the FB methodology takes into account multiple parameters and optimization conditions and therefore better reflects the actual circumstances in the network. The methodology for calculating the flows of power derives from the Commission Regulation (EU) 2015/1222 on the Establishment of CACM regulation (Article 20) and represents an important part of the European Target Model. The methodology contributes to reducing the price differences between national electricity markets, which leads to more stable prices, and increases the social benefits of the involved countries.

This paper will provide historical overview of the Core FB MC project, which is based on the decision of the Agency for the Cooperation of Energy Regulators (ACER) on November 17th, 2016. It will further on provide a presentation of all the working groups and their tasks within the FB MC project, high-level architecture and information flows, a detailed description of test processes divided into separate test

Given that the project is still in the implementation phase, and that Croatia is part of it since 2016, article will look at the local perspective and expectation from the moment of realization of the project, but will as well give an overall progress picture of the energy market and energy trading for the entire Core region.

\section{KEYWORDS}

Core Flow-Based Market Coupling (Core FB MC), Flow-Based Methodology, Single Day-Ahead Coupling (SDAC), Nominated Electricity Market Operator (NEMO), Agency for the Cooperation of energy Regulators (ACER), Core capacity calculation region (Core CCR), Power exchange, Energy market, Energy trading.

\section{HISTORICAL OVERVIEW}

The FB MC was initiated in June 2007 in CWE region (including Belgium, France, Netherlands and German-Austrian- Luxembourgish bidding zone) with a Memorandum of Understanding between Energy Ministers, Transmission System Operators (TSOs), Power Exchanges (PXs), National Regulatory Authorities (NRAs), and Market Parties Platforms. After 8 years of developing FB methodology, it was successfully implemented in May 2015 by the transmission system operators (TSO). In June 2016 the Core capacity calculation regions (Core CCR) was created based on the ACER decision 06/2016 on the electricity TSOs proposal for the determination of Core CCRs. In September 2017 Flow-Based Capacity Calculation Methodology developed jointly by all Core CCR TSOs was submitted to regulatory authorities (NRAs) for adoption based on the Article 20 of CACM regulation. In April 2018 the methodology was returned with a request for amendment. Two months later the TSOs resubmitted the methodology. Eventually, the NRAs did not reach a unanimous decision. The methodology was escalated to ACER and in the final form published in February 2019. [3] 


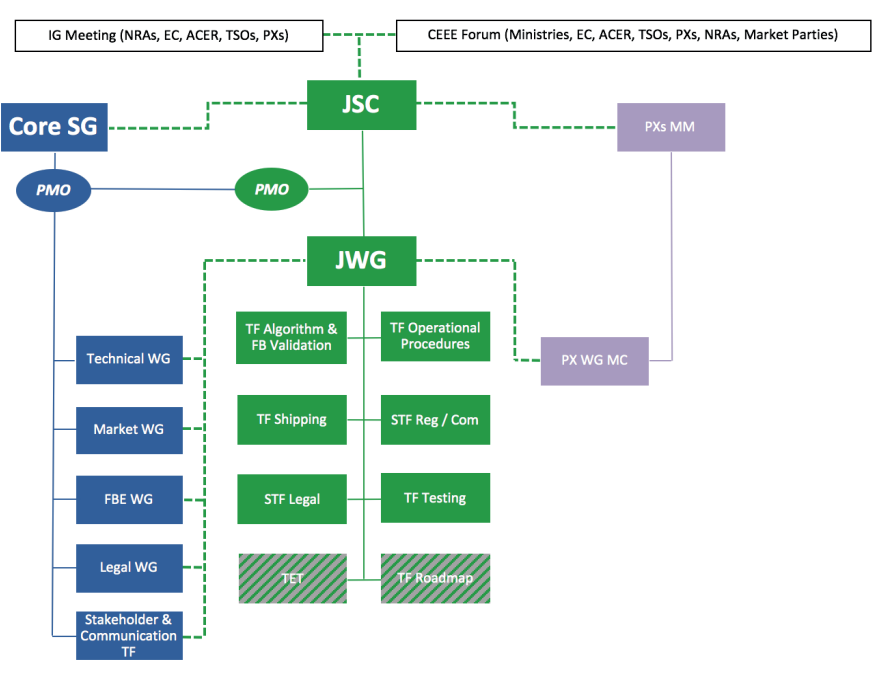

Table 1. TSOs and NEMOs - project parties [1]

\begin{tabular}{|c|c|c|c|c|c|c|c|c|c|c|}
\hline \multirow{2}{*}{ TSO } & \multirow{2}{*}{$\begin{array}{c}\text { AT } \\
\text { APG }\end{array}$} & \multicolumn{2}{|c|}{ DE } & \multirow{2}{*}{\begin{tabular}{|c|} 
SK \\
SEPS
\end{tabular}} & \multirow{2}{*}{$\begin{array}{c}\text { CZ } \\
\text { CEPS }\end{array}$} & \multirow{2}{*}{$\begin{array}{l}\text { PL } \\
\text { PSE }\end{array}$} & \multirow{2}{*}{$\begin{array}{c}\text { HU } \\
\text { MAVIR }\end{array}$} & \multirow{2}{*}{$\begin{array}{c}\text { SI } \\
\text { ELES }\end{array}$} & \multirow{2}{*}{$\begin{array}{c}\text { HR } \\
\text { HOPS }\end{array}$} & \multirow{2}{*}{$\begin{array}{c}\text { R0 } \\
\begin{array}{l}\text { Transe- } \\
\text { lectrica }\end{array}\end{array}$} \\
\hline & & $\begin{array}{c}\text { Tennet } \\
\text { DE }\end{array}$ & $\begin{array}{c}50 \\
\text { Hert女 }\end{array}$ & & & & & & & \\
\hline \multirow[t]{2}{*}{ NEMO } & $\begin{array}{l}\text { EXAA } \\
\text { EPEX }\end{array}$ & \multicolumn{2}{|c|}{$\begin{array}{l}\text { EXAA } \\
\text { EPEX }\end{array}$} & \multirow[t]{2}{*}{ OKTE } & \multirow[t]{2}{*}{ OTE } & $\begin{array}{l}\text { TGE/ } \\
\text { EPEX/ }\end{array}$ & \multirow[t]{2}{*}{ HUPX } & \multirow[t]{2}{*}{ BSP } & \multirow[t]{2}{*}{ CROPEX } & \multirow[t]{2}{*}{ OPCON } \\
\hline & EMCO & EM & & & & EMCO & & & & \\
\hline
\end{tabular}

In addition to the above participants, France, Germany, Belgium, Netherlands and Luxembourg have additional representatives (TSOs) in the project listed in Table 2. [1]

Table 2. TSOs - additional project parties [1]

\begin{tabular}{|c|c|c|c|c|c|c|}
\hline & FR & \multicolumn{2}{|c|}{ DE } & BE & NL & LU \\
\hline TSO & RTE & Amprion & TransnetBW & Elia & Tennet NL & CREOS \\
\hline
\end{tabular}

Figure 1 shows a symbolic map of Europe with the market Core CCR countries.

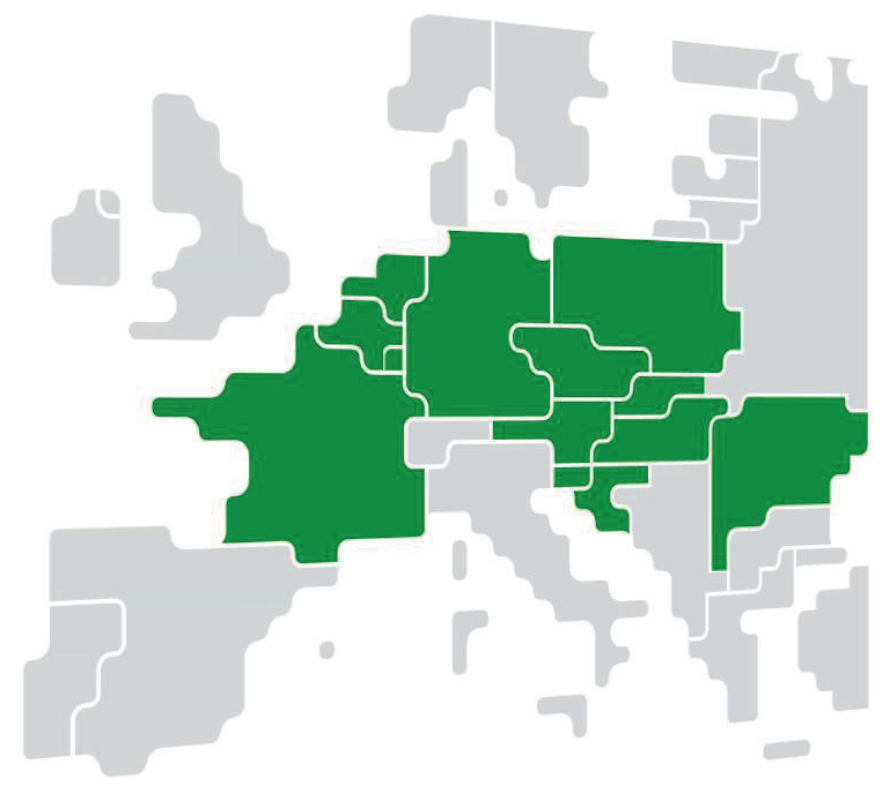

Figure 1. Core CCR

\section{WORKING GROUPS}

In order for the project to be realized, established are several working groups (WG) and task forces (TF), responsible for carrying out specific tasks. The list of the present working groups is provided in Figure 2.
Figure 2. Core FB MC working groups

Joint Steering Committee (JSC) shall:

- Be responsible for signing off the most important deliverables and in case escalation is needed, they will be the decisional body

- Approve costs and budget

- Delegate tasks to Project bodies

- Supervise the progress of the Project (roadmap) and work of the Project bodies, in particular, JWG and PMO

Project Management Office (PMO) shall:

- $\quad$ Support JSC in organizational matters

- Support TF leaders in all preparation and coordination activities for the respective tasks. The PMO participates in all conference calls, draft meeting minutes and ensures the follow-up of issues and actions.

Joint Working group (JWG) shall:

- Ensure and organize the fulfilment of the tasks set by JSC

- Provide JSC with reports and decision proposals prepared by itself or the other Project bodies

TF Algorithm \& FB Validation shall:

- Discuss and assess results of Internal Parallel Run that is provided by Core FB CC Project, Algorithm Smoke test and Acceptance test that will be provided by PCR, External Parallel Run, Member simulation testing and identify possible issues/risks during implementation

- Further evaluate performance of capacity calculation and allocation after Go-Live

TF Operational Procedures shall:

- Identification of the operational procedures needed for Core FB MC

- Translation of the Market Design for Implementation into respective processes and procedures

- Elaboration of respective documentation, i.e. Core FB MC Operational Procedures;

- Ensure compatibility between Core FB MC (including also TSO side result verification procedures if applied) and SDAC pre-coupling and post-coupling procedures while complying with Regulation (EU) 2015/1222

- Validate and if needed update all above listed sets of procedures after testing, if needed

- Update all above listed sets of procedures after NRAs review and approval, if needed

- Define rules for the Operational System Committee (OPSCOM) (related to pre- and post- coupling processes)

TF Shipping shall:

- Design the overall shipping and clearing solution for Core FB MC

- Design the implementation process for the shipping and clearing solution 


\section{Supportive TF Reg/Com shall:}

- Draft Press Releases based on JWG MC request

- Elaborate a Communication Plan taking into consideration all necessary stakeholders information requirements, legal obligations and experience from comparable projects

- $\quad$ Plan and organize the workshops for external stakeholders

- $\quad$ Prepare market training documents together with other TFs and JWG and interact with the market participants and stakeholders

- Manage general communication with the market participants

- $\quad$ Draft answers for journalists when requested by JWG

- Provide project information for electronic platforms (i.e. website)

Supportive TF Legal shall:

- Design the overall contractual framework for Core FB MC

- Ensure compatibility of Core contractual framework with other relevant regional projects and $\mathrm{CACM}$

- Design the schedule of the agreements delivery

- Draft the common contract(s)

- Participate in the legal check of the agreements

- Identify the necessary contractual framework for shipping and crossborder clearing in the Core region based on inputs of TF Shipping

TF Testing shall:

- Design of overall testing activities which should be divided into separate test phases (i.e. development of the Master Test Plan)

- Coordinate isolated system, integration, simulation, SDAC, member and acceptance tests

- Assess test results and prepare the test end report

- Prepare the approval of the technical and procedural readiness of project parties as a precondition for Core FB MC Go-live

- $\quad$ Align its activities and cooperate with TF Operational Procedures and

\section{- $\quad$ TF Shipping}

According to the above tasks, there are several important milestones to be finished before the Core Flow-Based Market Coupling goes live [3]:

- Market Design for Implementation - Document containing the description of the entire normal business process for coupling dayahead markets including issues such as shipping arrangements, congestion income collection and aggregation, IT infrastructure and data communication (JWG; TF Shipping)

- $\quad$ Procedures design - normal, back-up, fallback, rollback, special and other procedures (TF Operational Procedures)

- Simulation and validation - tests performed in the test environment of the computational algorithm (TF Testing)

- External parallel run - real time testing by comparing the results of the current NTC calculation method and the FB method for the period of six months (TF Algorithm \& FB Validation)

- External implementation - design, development and implementation of local IT systems of individual project parties

- Final market coupling testing - a lot of tests performed before go-live (TF Testing)

\section{HIGH-LEVEL ARCHITECTURE AND INFORMATION FLOWS}

The high-level process architecture for the normal operation of a flowbased day-ahead market coupling in the Core CCR, shown in Figure 3 , includes required systems, as well as produced and exchanged information represented by arrows.

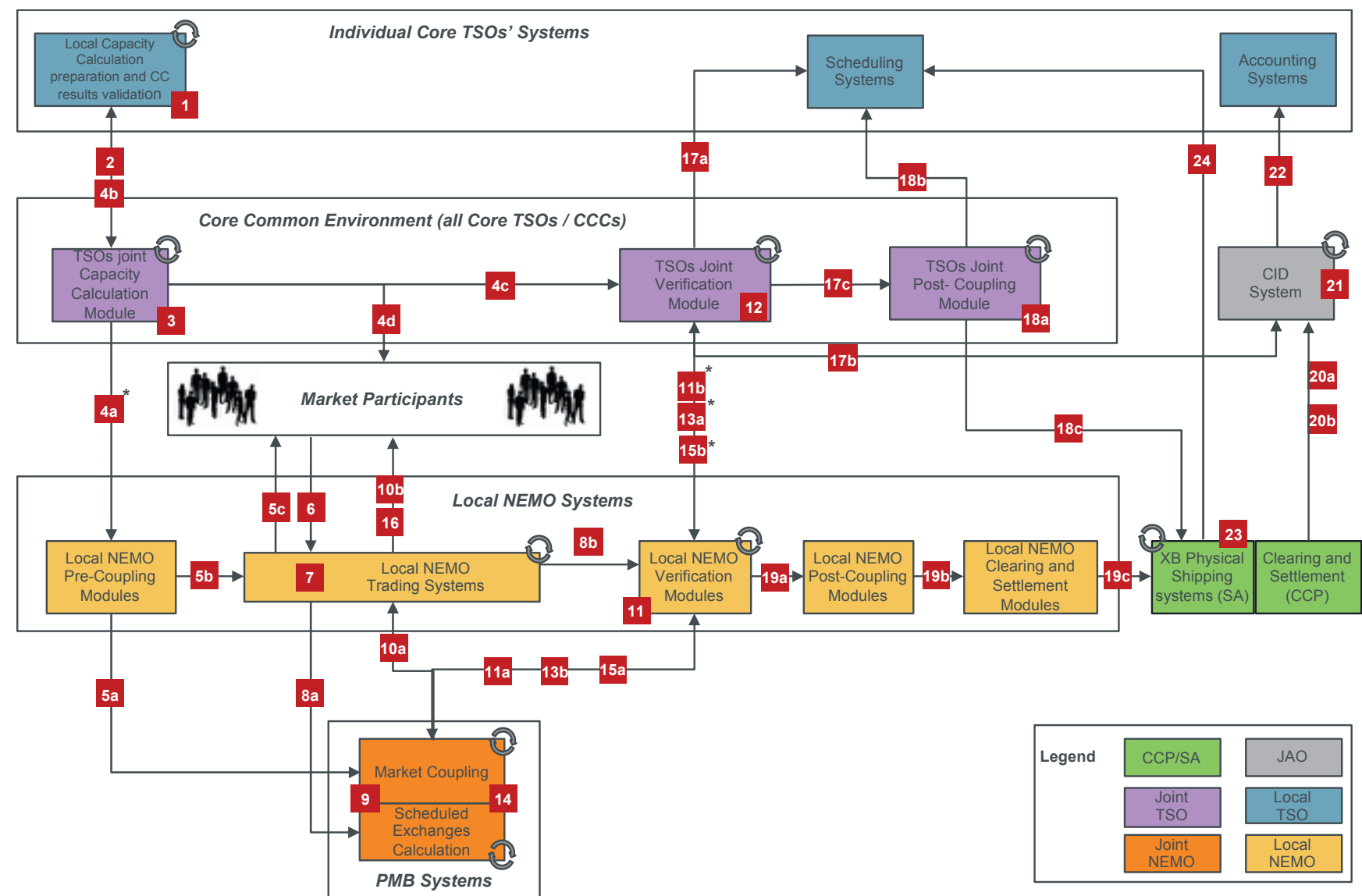

Figure 3. High-level process architecture 


\section{THE MARKET COUPLING PROCESS}

The market coupling process is divided in three phases: Pre-Coupling, Coupling and Post-Coupling phase. The following subchapters briefly explain each of the phases.

\section{PRE-COUPLING}

For Pre-Coupling activities, the following tasks have to be managed:

- $\quad$ CDD calculation - TSOs are fully responsible for capacity data domain provision, verification, adjustment and approval of final CDD, as well as delivering them to NEMOs (Local NEMO Pre-Coupling Systems).

- $\quad$ Final CDD publication - TSOs are responsible for publication of final CDD on the ENTSO-E Publication Platform. NEMOs are responsible for publication of final CDD on Local NEMOs' Trading Platforms for local market participants.

- Collection of energy buy/sell orders and their processing - NEMOs are responsible for collecting and aggregation of market participants buy/sell energy orders. NEMOs deliver aggregated orders to PMBs. NEMOs are responsible for delivering final CDD to PMBs and Trading Systems.

\section{COUPLING}

Market coupling results containing at least but not limited to:

- a single clearing price for each bidding zone and market time unit in EUR/MWh and;

- a single net position for each bidding zone and each market time unit and;

- information which enables determination of an execution status of orders;

- $\quad$ scheduled exchanges;

Market coupling results are calculated by NEMOs via PMB Systems in accordance with the SDAC process and related procedures.

The Coupling is under the responsibility of NEMOs, however, the TSOs are responsible for providing the final confirmation of the results.

\section{POST-COUPLING}

The post-coupling activities consist of cross border physical shipping (Cross border scheduling), clearing and settlement of scheduled exchanges. Transfer of the energy from one bidding zone to another bidding zone is performed by a designated institution(s) (same or a different designated institution) for cross-border scheduling and cross-border clearing and settlement. Congestion income is collected by designated institutions preforming cross-border clearing and settlement and transferred to the congestion income distributor (CID) and shared between concerned TSOs.

For post-coupling activities, the following cross-border relevant tasks have to be performed:

- Cross border scheduling, cross border clearing and settlement (physical and financial shipping);

- $\quad$ Sending of the congestion income to CID;

- Calculation and distribution of congestion income shares by CID (on multilateral basis between CID and TSOs).

Additionally, in case of some problems arising while performing normal market coupling processes, provided are two solutions depending on the nature of the problem itself.

\section{FALLBACK SOLUTION}

In case the day-ahead market coupling cannot be run with the normal timings and backup procedures do not solve the issue, it may be needed to proceed with different decoupling situations and to allocate respective cross border capacities via a fallback solution (applying fallback procedures).

\section{ROLLBACK SOLUTION}

During the first six weeks after the Core FB MC project go-live, if the TSOs and/or the NEMOs are facing regular serious problems, which cannot be solved within acceptable period, a Rollback Situation can be triggered to avoid persistent uncertainties for Market Participants. The Rollback will end with the resolution of the problems and the announcement of new Go-live by the Core FB MC project JSC.

\section{HARMONIZATION OF PRINCIPLES AND CHARACTERISTICS}

In accordance with the relevant methodologies developed under the CACM Regulation, it is necessary to harmonize the basic principles and characteristics of market coupling, described in table 3 , among project participants.

Table 3. Comparison of SDAC and CORE FB MC [1]

\begin{tabular}{|c|c|c|}
\hline Time zone & & CET/CEST \\
\hline Implemented countries & SDAC & Core CCR \\
\hline Type of coupling & ATC based MC & FB based MC \\
\hline Providing the Capacities to NEMOs & $10: 20$ & $10: 30$ \\
\hline Standard Publication of Capacities & $10: 30$ & $10: 30$ \\
\hline $\begin{array}{l}\text { Orderbook DA Market Gate Closure Time } \\
\text { of NEMOs }\end{array}$ & $12: 00$ & $12: 00$ \\
\hline $\begin{array}{l}\text { Standard Publication of preliminary } \\
\text { Results by NEMOs }\end{array}$ & $12: 42$ & $12: 42$ \\
\hline $\begin{array}{l}\text { Standard Publication of Final Results by } \\
\text { NEMOs and TSOs }\end{array}$ & $12: 56$ & $\begin{array}{l}\text { 12:55 for NEMOs } \\
\text { After 12:55 for TSOs }\end{array}$ \\
\hline Nomination Deadline (XB) & $14: 30$ & $14: 301$ \\
\hline Cross-border Flow decimals [MWh] & & One digit \\
\hline $\begin{array}{l}\text { Price step of Market clearing price [ } \epsilon \text { / } \\
\text { MWh] }\end{array}$ & & Two digits \\
\hline Min/Max prices [€/MWh] & & $-500 /+3000$ \\
\hline Second Auction Trigger [€/MWh] & & $-150 /+1500$ where applicable \\
\hline Volume Tick size of bids [MWh] & & One digit \\
\hline Price step for bids [ $€ / M W h]$ & & Two digits \\
\hline
\end{tabular}

\section{TEST PROCESSES}

The implementation phase of the Core Flow-Based Market Coupling project comprises a joint testing period with all involved parties which can be divided in the seven phases: Isolated System Test, Pre-Integration Test (Pre-FIT), Full Integration Test (FIT), Simulation Test, Single Day-Ahead Coupling (SDAC) Simulation Test, Member Test and Acceptance Test. [2]

Characteristics of these tests are [2]:

- Isolated System Test demonstrates that all individual systems under responsibility of individual Parties are ready for further connected testing.

- $\quad$ The Pre-FIT Test demonstrates that communication between the Flow-based systems involved meets the infrastructure requirements and that the used files are compatible and can be exchanged. In addition, the performance of a Normal day is one of the aims of this phase.

- $\quad$ The FIT test demonstrates that communication between the involved systems meets the functional requirements to support the FB MC process. Both Normal days, as well as Backups and special scenarios, are part of the test that will be performed during this phase.

- $\quad$ The Simulation Test finally demonstrates that the common and local procedures fit the purpose they are developed for; the developed systems meet the functional and quality requirements and the local 
and common procedures.

- $\quad$ The SDAC Simulation Test demonstrates the Simulation test with SDAC project parties.

- $\quad$ Member Test demonstrates the FB MC daily trading process to the market participants.

- $\quad$ Acceptance Test demonstrates that there are no defaults that prevent the GO-live.

The Testing TF proposes to the JWG, who further distributes it to the JSC as decision body, to accept the solution if all scenarios and levels are successfully performed and all known issues are registered and acceptable for all parties involved. [2] Figure 4 shows the organization of Testing TF.

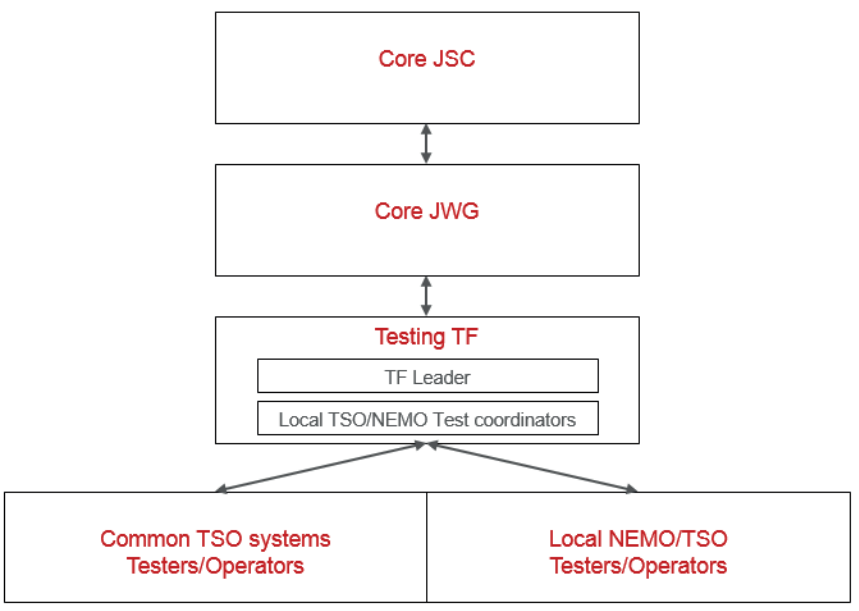

Figure 4. Testing TF organization [2]

During FIT and SIT phase there are several systems needed depending on the part of the market coupling process. These systems are listed in Figure 5.

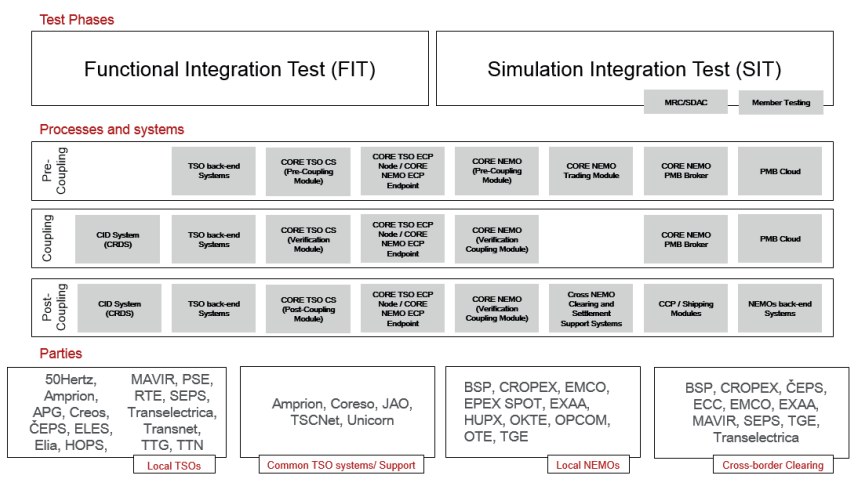

Testing phases and their approximate duration are described in Figure 6 At the time of writing this article, the Test Phase 2 was, due to unforeseen delays, postponed for a few months. Test Phase 1 was finalized in Q4 2019.

\begin{tabular}{|l|c|} 
& $\begin{array}{c}\text { No. of testing } \\
\text { (working) days }\end{array}$ \\
\hline TESTING ACTIVITIES & \\
\hline Test Phase 1 & \\
\hline Draft Master Test Plan (planning and approach) & \\
\hline Sign off Master Test Plan & \\
\hline Test Phase 2 & \\
\hline Phase 1: Isolated System Test - local testing & $5+8$ \\
\hline Phase 2: Pre-FIT & $30+8$ \\
\hline Phase 3: Full Integration Test (FIT) & $20+4$ \\
\hline Phase 4: Simulation Test & 10 \\
\hline Phase 5: SDAC Simulation Test & 10 \\
\hline Phase 6: Member Test & 3 \\
\hline Phase 7: Acceptance Test & 5 \\
\hline Phase 8: Finalization of Test End Report & 15 \\
\hline Sign off Joint MC testing & \\
\hline
\end{tabular}

Figure 6. Test planning [2]

\section{CONCLUSION}

The overall common goal of the project is to successfully launch the Core FB MC in line with CACM Regulation. The implementation of the FB methodology in practice will optimize the allocation of available trading capacity, which in market integration optimizes the efficiency of energy trading by allocating cross-border transmission capacities between coupled dayahead markets, taking into account the physical constraint of the network in a more precise and detailed manner (variable production from RES). In FB MC, the allocation of transmission capacity is partly done simultaneously with the market clearing, unlike NTC/ATC where the allocation of transmission capacity is done ex-ante the market clearing. As such, more transmission capacity is made available to the market in FB MC. This is confirmed by off-line test runs of the FB MC, which indicate an increase in social welfare due to more transmission capacity, compared to NTC/ ATC. It also reduces price difference between the national electricity markets (prices are more stable). Given that Croatia is part of the FB MC project since 2016, it is expected, that after its implementation, a utilization of cross border capacity will be higher, which will consequently lead to the higher volume on CROPEX, while maintaining the required level of the network security by more efficient congestion management.

Figure 5. Required systems during testing [2]

BIBLIOGRAPHY [1] Core FB MC JWG, Market Design for Implementation (MDfl) - Core Flow Based Market Coupling Project (March 2019)

[2] Core FB MC Testing TF, Master Test Plan - Full Integration and Simulation Test Core Flow-Ba- sed Market Coupling (December 10th 2019)

FOOTNOTES

[3] https://www.jao.eu/support/resourcecenter/overview?param
eters $=\% 7 \mathrm{~B} \% 221$ sCore $\% 22 \% 3$ eters $=\% 7 \mathrm{~B} \% 22$ IsCore $\% 22 \% 3$
The deadline 14:30 applies If the $\mathrm{MC}$ results are available between 12:56 and 13:20. If the MC results are available after $13: 20$, the deadline is postponed to 15:30 